\title{
Biosafety Requirements for Autopsies of Patients with COVID-19: Example of a BSL-3 Autopsy Facility Designed for Highly Pathogenic Agents
}

\author{
Martina Loibner ${ }^{\mathrm{a}}$ Christine Langner $^{\mathrm{a}}$ Peter Regitnig ${ }^{\mathrm{a}} \quad$ Gregor Gorkiewicz $^{\mathrm{a}}$ \\ Kurt Zatloukal ${ }^{a}$ \\ ${ }^{a}$ Diagnostic and Research Center for Molecular Biomedicine, Institute of Pathology, Medical University of Graz, \\ Graz, Austria
}

\section{Keywords}

Biosafety · COVID-19 · Autopsy · Biosafety level 3 laboratory

\begin{abstract}
Information obtained from autopsies of patients infected with high-risk pathogens is an important pillar in managing a proper response to pandemics, particular in the early phase. This is due to the fact that autopsy allows efficient evaluation of comorbidities for risk assessment, as well as identification of key pathophysiological and molecular mechanisms in organs driving the severity of disease which might be important targets for therapeutic interventions. In the case of patients who have died of infection with unknown pathogens, isolation and culture of pathogens from the affected organs is another important opportunity for a proper response to (re)emerging infectious diseases. However, the situation of COVID-19 demonstrated that there were concerns about performing autopsies because of biosafety risks. In this review we compare requirements for biosafety level 3 (BSL-3) laboratories from the European Commission and the World Health Organization and summarize specific recommendations for postmortem analysis of COV-
\end{abstract}

ID-19-deceased patients from the Centers for Disease Control and Prevention. Furthermore, we describe in detail a BSL-3 facility with enhanced protection of personnel and an environment that has been designed for performing autopsies, biobanking of collected tissue specimens, and culture of pathogens in cases of high-risk pathogen infections and report on the experience obtained in operating this facility in the context of COVID-19.

(c) 2020 S. Karger AG, Basel

\section{Introduction}

Increasing population densities, increased mobility, and changing habitats of humans and animals, as well as climate change, are major drivers of the appearance of new or reemerging pathogens and pandemics $[1,2]$, which may cause major threats to global socioeconomic systems. Autopsy plays an important and generally underestimated role in disease surveillance and a proper response to pandemics. Firstly, autopsies are one of the most reliable methods for identifying the cause of death, including evaluation of the functional role of co- 
morbidities, which is important for risk assessment of infectious diseases [3]. For instance, there was major variation in the estimated reported case fatality rate of the swine origin influenza A (H1N1) pandemic, which made risk assessment difficult [4]. This overestimation, especially of the number of people who died in the early phase of the pandemic, was most probably due to the relatively advanced age of patients with a fatal course and the lack of knowledge of comorbidities [5]. Also with COVID-19 there is a large variation in case fatality rates reported in different countries, which has resulted in major discussions regarding the appropriateness of measures taken to reduce spread of the disease and save capacities in hospitals [6,7]. A second very important role of autopsies in pandemics is to obtain insight into the pathogen-host interaction and the pathophysiology of organ damage. This is only possible via comprehensive pathological and molecular analyses of affected organ samples that have been properly collected and biobanked during autopsy $[8,9]$. Thirdly, autopsy may help to identify and quantify pathogens by immunohistochemical and molecular testing, and it allows isolation of pathogens from organ samples centrally involved in the disease $[3,10]$. However, there was reluctance to perform autopsies during the early phase of the COVID-19 pandemic and some authorities, such as the Italian Ministry of Health, declared that, for the entire period of the emergency phase, autopsies or postmortem diagnostic studies should not be performed in fullblown cases of COVID-19 [11]. This restriction, however, did not apply to autopsies for research purposes. Also the Robert Koch Institute (Germany) advised not performing autopsies because of biosafety concerns [12, 13], which was later revised after intervention by pathologists from Germany.

\section{Biosafety}

Biosafety measures must be applied for all autopsies even if the autopsy is performed for another disease such as cancer or degenerative disorders, since some infectious diseases are not diagnosed before death or, for example, there might be an infectious pathology such as tuberculosis mimicking a tumor on radiology. So all autopsies need the application of appropriate biosafety measures in order to protect healthcare workers and the environment. Generally, biosafety measures depend on the risk group of the pathogen, the infection route (e.g., aerosol, droplets, or blood), the pathogen concentration in organs and body fluids, the stability of the pathogen in corpses and the environment, and the risk of exposure and injury by performing autopsies. In the event that the pathogens are unknown or the risk group has not yet been defined, the best possible protection of personnel and the environment should be achieved. The biosafety requirements are typically higher for autopsies than for laboratory testing, because of the higher risk of handling infectious material in the context of autopsies (i.e., risk of contamination of personal protective equipment [PPE], generation of droplets and aerosols, risk of injury by using sharp tools, etc.) compared to laboratory testing wherein critical analysis steps are performed in biosafety cabinets. Detailed guidance for laboratory testing of COVID-19-derived samples is provided by the World Health Organization (WHO) [14]. Autopsies are important particularly in the early phases of pandemics in order to support actions that are based on scientific evidence. This requirement goes hand in hand with the fact that in the early phases of pandemics many of the parameters required for risk assessment are not yet sufficiently investigated and defined. Therefore, a higher protection level for personnel and the environment might be required than in later phases of an outbreak.

SARS-CoV-2 has been classified as a risk group 3 (RG3) pathogen by the European Commission and several other organizations [15]. However, several groups in the Employment and Social Affairs Committee of the European Parliament only agreed to classify the virus that causes COVID-19 as an RG-3 biological agent after adding more safeguards to protect all workers [16]. This discussion mirrored the fact that mandatory requirements for biosafety level 3 (BSL-3) do not include further specified PPE requirements. BSL-3 requirements are defined at different levels, such as guidelines published by the WHO [17] or the European Commission [18], and are implemented in national legislation. General requirements include restricted access to the facilities, closed rooms with negative air pressure, wearing of PPE, and appropriate decontamination and waste inactivation (for comparison of the European Commission Directive and the WHO guideline, see Table 1). These requirements are defined for RG-3 pathogens in general and the further specification has to be based on risk assessment for specific cases.

Concerning autopsies of SARS-CoV-2 infected patients, the Centers for Disease Control and Prevention (CDC) has published a guidance document that specifically addresses biosafety requirements for collection and handling of postmortem specimens [19].
Loibner/Langner/Regitnig/Gorkiewicz/ Zatloukal 
Table 1. Comparison of requirements for BSL-3 laboratories as specified in the EU Directive and the WHO Biosafety Manual

Annex V (indications concerning containment measures)

The workplace is to be separated from any other activities in the same building (recommended ${ }^{\mathrm{c}}$ ).

Not defined $^{\mathrm{b}}$

The workplace is to be sealable to permit fumigation (recommended ${ }^{\mathrm{c}}$ ).

Not defined ${ }^{\mathrm{b}}$

Not defined ${ }^{\mathrm{b}}$

Infected material including any animal is to be handled in a safety cabinet or isolation or using another suitable containment (if infection is by the airborne route).

Extract air to the workplace is to be filtered using HEPA or the like.

The workplace is to be maintained at an air pressure negative to the atmosphere (recommended ${ }^{c}$ ).

Surfaces impervious to water and easy to clean
Surfaces resistant to acids, alkalis, solvents, and disinfectants

Access is to be restricted to nominated workers only.

Efficient vector control, e.g., rodents and insects

Specified disinfection procedures

Safe storage of a biological agent

Personnel should shower before leaving the contained area (recommended $\left.{ }^{c}\right)$.

Validated inactivation process for the safe disposal of animal carcasses, on or off site

A laboratory is to contain its own equipment (recommended ${ }^{\mathrm{c}}$ ).

An observation window, or an alternative, is to be present so that occupants can be seen (recommended ${ }^{\mathrm{c}}$ ).

\begin{tabular}{ll}
\hline Not defined $^{\mathrm{b}}$ & $\begin{array}{l}\text { An autoclave for decontamination of contaminated waste material should be } \\
\text { available in the containment laboratory. }\end{array}$ \\
\hline Not defined $^{\mathrm{b}}$ & Backflow precaution devices must be fitted to the water supply. \\
\hline Not defined $^{\mathrm{b}}$ & $\begin{array}{l}\text { Medical examination of all laboratory personnel who work in containment } \\
\text { laboratories (BSL-3) is mandatory. }\end{array}$ \\
\hline
\end{tabular}

${ }^{a}$ Same requirements. ${ }^{b}$ This requirement is not mentioned in the respective document. ${ }^{c}$ The measures should, in principle, be applied unless the results of the assessment referred to in (EU) 2019/1833 article 3(2) indicate otherwise.
The laboratory must be separated from the areas that are open to unrestricted traffic flow within the building.

Anteroom doors may be self-closing and interlocking so that only one door is open at a time. A break-through panel may be provided for emergency exit use. Yes $^{\mathrm{a}}$

Windows must be closed, sealed, and break resistant.

A hand-washing station with hands-free controls should be provided near each exit door.

Open manipulations of all potentially infectious material must be conducted within a biological safety cabinet or other primary containment device.

When exhaust air from the laboratory (other than from biological safety cabinets) is discharged to the outside of the building, it must be dispersed away from occupied buildings and air intakes. Depending on the agents in use, this air may be discharged through HEPA filters.

There must be a controlled ventilation system that maintains a directional airflow into the laboratory room. A visual monitoring device with or without alarm(s) should be installed so that staff can at all times ensure that proper directional airflow into the laboratory room is maintained.

Yes $^{\mathrm{a}}$

Not defined ${ }^{b}$

Not defined ${ }^{b}$

Not defined ${ }^{b}$

Not defined ${ }^{\mathrm{b}}$

Not defined ${ }^{b}$

Not defined ${ }^{\mathrm{b}}$

Not defined ${ }^{b}$

Not defined ${ }^{b}$

Not defined ${ }^{b}$

An autoclave for decontamination of contaminated waste material should be

Medical examination of all laboratory personnel who work in containment boratories (BSL-3) is mandatory. 
The guidance specifies several issues as follows (shortened examples; for the full text, see the website of the CDC [16]):

General procedures:

- Aerosol-generating procedures such as the use of an oscillating bone saw should be avoided or attached to a vacuum shroud.

- Allow only one person to cut at a given time.

- Limit the number of personnel working in the autopsy suite.

- Use a biosafety cabinet for the handling and examination of smaller specimens.

- Use caution when handling needles or other sharps.

- A logbook for all workers participating in the postmortem and cleaning of the autopsy suite should be kept.

Facility requirements:

- Negative pressure to surrounding areas

- A minimum of 6 air changes per hour (ACH) for existing structures and $12 \mathrm{ACH}$ for renovated or new structures

- Air exhausted directly outside or through a high-efficiency particulate aerosol (HEPA) filter.

PPE requirements:

- Double surgical gloves interposed with a layer of cutproof synthetic mesh glove

- Fluid-resistant or impermeable isolation gown

- Waterproof apron

- Goggles or face shield

- N-95 or higher respirator

- Powered, air-purifying respirators with HEPA filters may provide increased worker comfort during extended autopsy procedures

- When respirators are necessary to protect workers, employers must implement a comprehensive respiratory protection program

- Surgical scrubs, shoe covers, and surgical cap should be used per routine protocols.

Doffing of PPE:

- Doff (take off) PPE carefully to avoid contaminating yourself and before leaving the autopsy suite or adjacent anteroom.

- After removing the PPE, discard the PPE into the appropriate laundry or waste receptacle. Reusable PPE (e.g., goggles; face shields; and powered, air-purifying respirators) must be cleaned and disinfected according to the manufacturer's recommendations before reuse.

- Immediately after doffing PPE, wash hands with soap and water for $20 \mathrm{~s}$. An alcohol-based hand sanitizer that contains $60-95 \%$ alcohol may be used. Ensure that hand hygiene facilities are readily available at the point of use (e.g., at or adjacent to the PPE doffing area).

Furthermore, guidelines on autopsies of COVID19-deceased patients have been published by various medical societies, and several institutions have described their in-house procedures $[8,20-28$ ] [for review and comparison of recommendations and guidelines, see 29].

\section{Example for the Design and Operation of a BSL-3}

Facility with Enhanced Protection of Personnel and

the Environment for Performing Autopsies

Here we describe the BSL-3 facility at the Medical University of Graz that has been designed specifically for performing autopsies involving highly pathogenic agents or unknown pathogens, handling frozen sections to facilitate a fast diagnosis, processing of infectious samples for diagnostics, collection of samples for biobanking, and isolation and culture of pathogens (Fig. 1). We built on experience accumulated during participation in EUfunded research programs aimed at the design and construction of a European research infrastructure for highly pathogenic agents (ERINHA; https://www.erinha.eu/), which included several of the European BSL-4 laboratories. Therefore, several biosafety features mandatory for BSL-4 laboratories were implemented in order to obtain a higher level of protection of health care workers, researchers, and the environment. The rationale for implementing higher biosafety features was to minimize the risk for personnel performing autopsies of patients who died from unknown pathogens or pathogens for which a risk classification has not yet been performed. This was achieved by a negative pressure system, restricted access via airlock, the use of liquid-impermeable full body suit PPE including powered air-purifying respirators, and optimized decontamination procedures comprising a chemical shower to decontaminate personnel and sealed body bags after autopsy. Furthermore, the biosafety concept was complemented by measures to prevent unauthorized access to and theft of biobanked pathogens or pathogencontaining samples.

A specific challenge to be addressed in the design was the limited available space and that there were no floors above or below the laboratory for supply and disposal or technical rooms, as is typically the case in high-security laboratories. The BSL-3 pathology laboratory has a work area of $68 \mathrm{~m}^{2}$, and areas for the lock, sanitary, and technical areas account for approximately $24 \mathrm{~m}^{2}$. The laboratory has a 2-stage negative pressure system $(2 \mathrm{x}-30 \mathrm{~Pa}$ for the airlock and laboratory, respectively) with HEPA filters (HEPA H14) and it has $8 \mathrm{ACH}$.
40

Pathobiology 2021;88:37-45 DOI: $10.1159 / 000513438$
Loibner/Langner/Regitnig/Gorkiewicz/ Zatloukal 

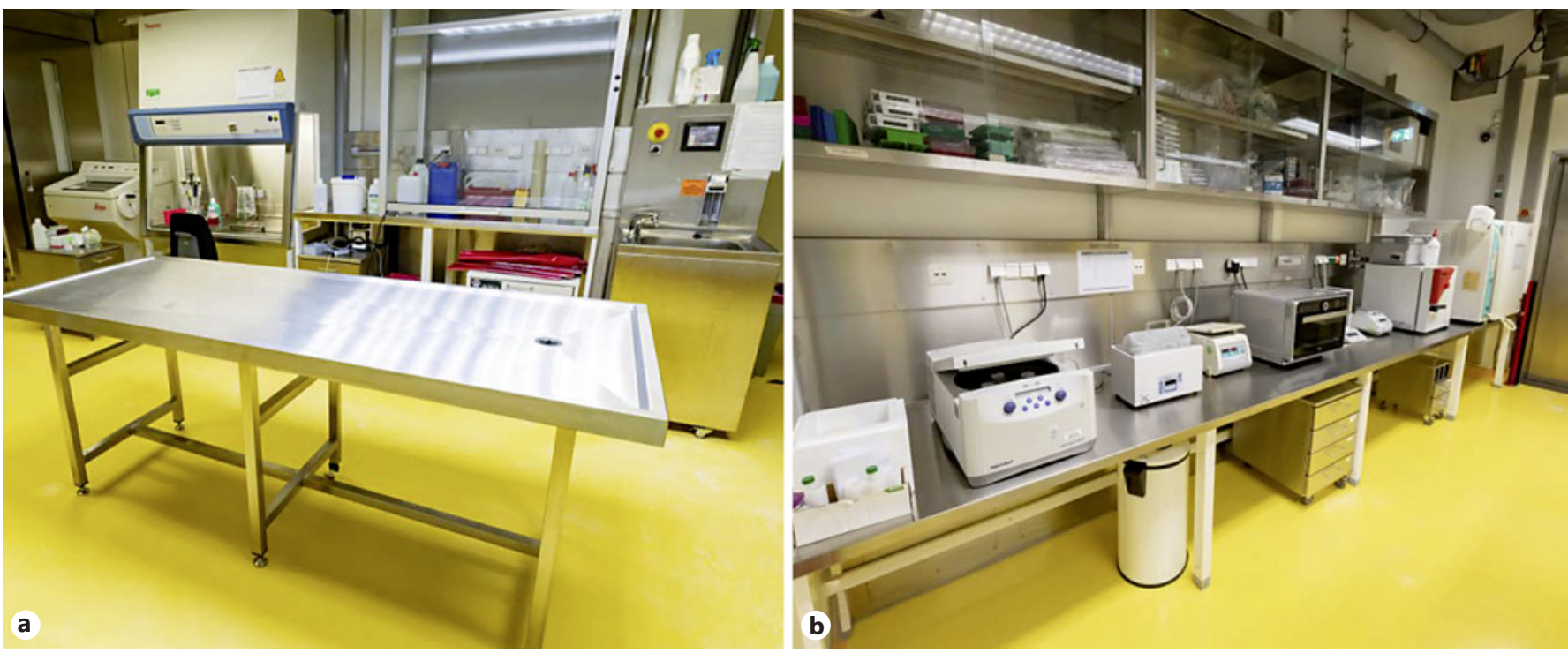

Fig. 1. Interior view of the BSL-3 autopsy and laboratory area. a Room 1 with an autopsy table, a chemical hood, a class II cabinet, and cryo cut. b Room 2 with laboratory equipment for cell and virus culture.
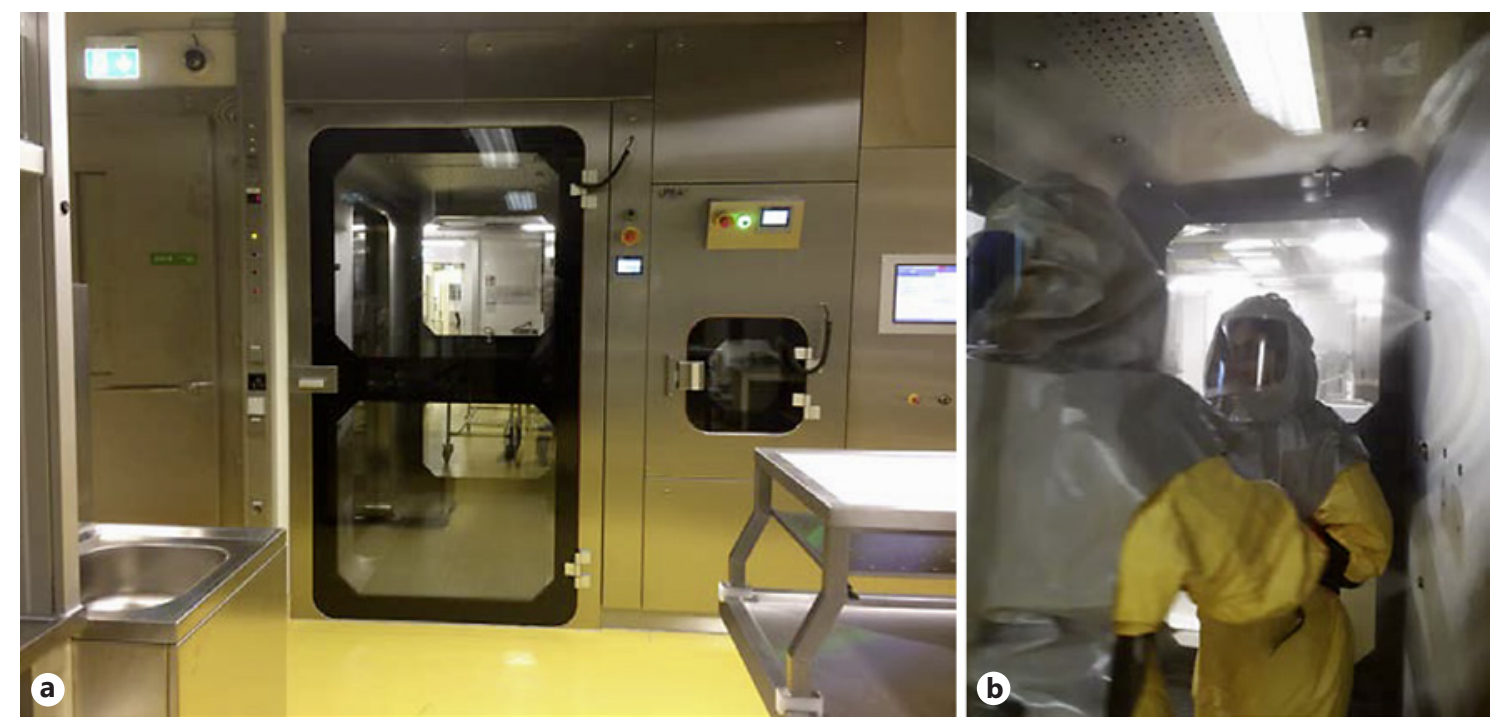

Fig. 2. a Lock area with a personnel entrance, a chemical shower, a material lock, and a pass-through autoclave (left to right). b Chemical shower (fumigation step).

Room decontamination is performed with hydrogen peroxide which is produced by a gas generator outside the containment and then distributed in the laboratory area. Furthermore, UV radiation is available for daily decontamination and wipe disinfection (e.g., for prions). Another special feature of the laboratory is the chemical shower for personnel and corpses, which has been newly designed for these applications and offers the opportunity for different decontamination processes to be developed, tested, and used (Fig. 2). For decontamination, peracetic acid or chlorine dioxide is used for the chemical shower and chlorine dioxide is used for the material lock.

The use of water in the laboratory has been reduced to a minimum and water is heat inactivated within the laboratory. For autopsies, water supply and removal of waste 

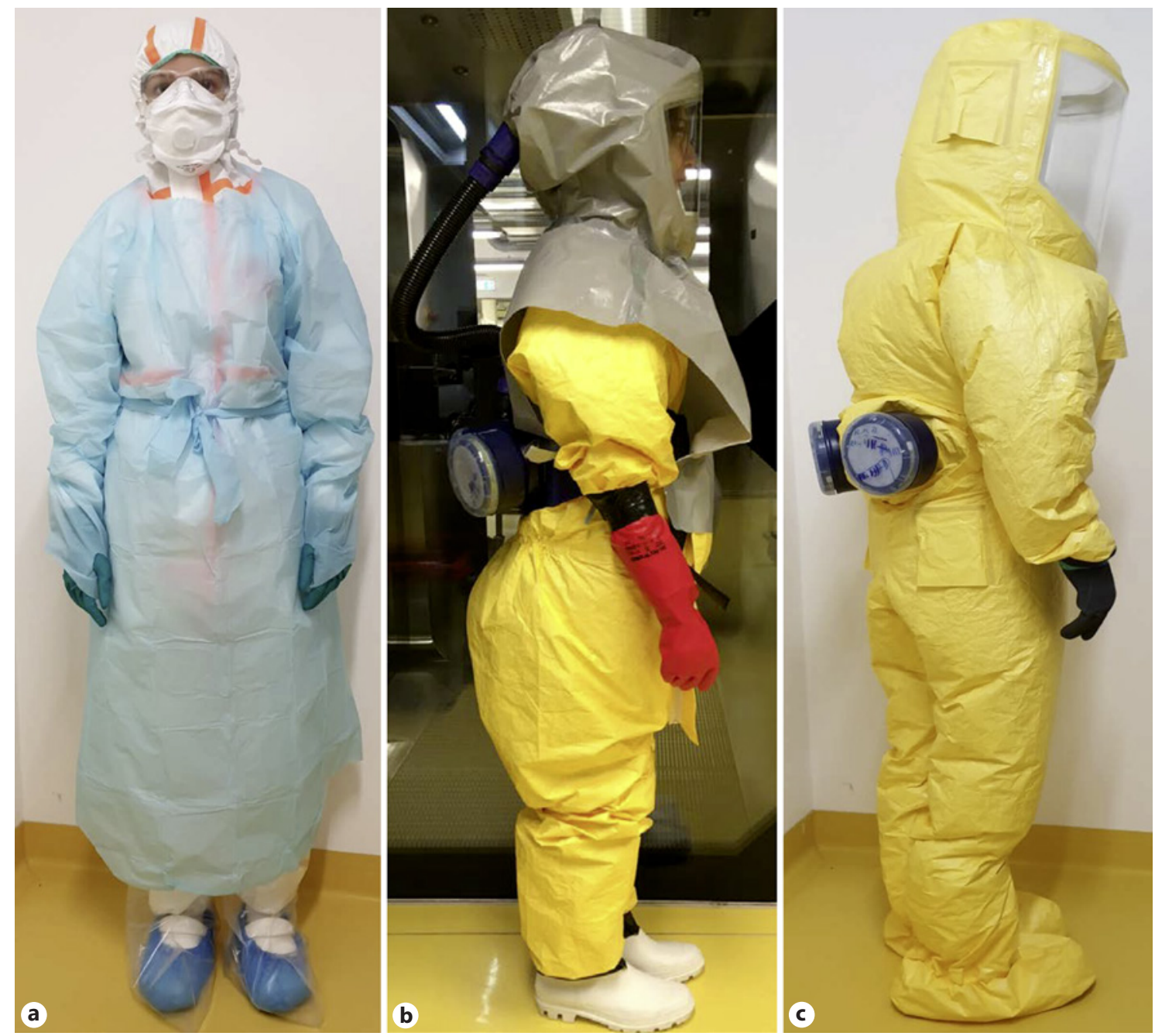

Fig. 3. Three different types of PPE. a PPE light. b PPE-heavy variant 1. c PPE-heavy variant 2.

water are provided locally at the autopsy table by peristaltic pumps. Waste water is collected in plastic containers for inactivation by autoclaving. Waste water pipes in the floor were avoided to facilitate decontamination. Our practical experience showed that the use of water can be avoided during most autopsies, and small amounts of ascites or pleural fluid can be easily removed using cellulose paper towels, which are collected in single-use and sealed waste containers. For biobanking of tissue samples, two $-80^{\circ} \mathrm{C}$ freezers (one freezer serves as backup) are available. The use of liquid nitrogen is avoided in the laboratory because of safety and maintenance issues.

Depending on the requirements, 3 different types of PPE are foreseen (Fig. 3). The single-use "PPE light" consists of surgical scrubs and 2 layers of disposable material (overalls, inner gloves, inner shoe covers, an FFP3 mask, glasses, a liquid-impermeable apron with sleeves, outer gloves, outer shoe covers and a face shield for postmortems). PPE light is used for autopsies involving RG-3 pathogens such as SARS-CoV-2 or multiresistant tuberculosis, and when decontamination by chemical shower is not feasible (e.g. in the case of Creutzfeldt-Jakob disease, requiring wiping decontamination with sodium hydroxide solution). After work with PPE light, both disposable layers are deposited according to a detailed doffing protocol in containers for autoclave waste. The outermost potentially contaminated PPE layer (outer shoe cover, liquid-impermeable apron, and outer gloves) is deposited in the laboratory in the doffing area next to the personnel lock and the inner layer (overall, inner shoe cover, face shield, FFP3 mask, and inner gloves) in the first negative pressure level of the airlock. The changing 
area with the personal shower can then only be entered with the surgical scrubs.

"PPE heavy" comprises 2 variants and is applied in cases of pathogens with unknown risk or when propagating SARS-CoV-2 (e.g., culture of virus isolates, and infection experiments with high-titer virus preparations for testing of antiviral compounds or neutralizing antibodies). PPE heavy includes a pathogen- and liquid-impermeable coverall and reusable blower filters for the head or wholebody ventilation. Variant 1 consists of a Tychem ${ }^{\circledR}$ protective suit $\left(\right.$ Tychem ${ }^{\circledR} 2000$ C, category 3, type 3/4/5/6; Haberkorn $\mathrm{GmbH}$, Austria) on which gloves and boots are sealed with adhesive tape. The protective hood $\left(3 \mathrm{M}^{\mathrm{TM}}\right.$ Versaflo ${ }^{\mathrm{TM}}$ Premium Suspension Chemical Hoods; FisherScientific) is ventilated by a powered air-purifying respirator (Jupiter ${ }^{\mathrm{TM}}$ Powered-Air Respirator; Haberkorn) equipped with Type ABEKP filters (3M ${ }^{\mathrm{TM}}$ Jupiter $^{\mathrm{TM}}$ Powered-Air Turbo Filters; Haberkorn). Variant 2 consists of a closed Tychem ${ }^{\circledR}$ full-body protective suit (3S ProChem III CPM; 3S-Arbeitsschutz GmbH, Germany) with integrated gloves and foot parts. This variant provides additional protection through the positive pressure generated by the powered air-purifying respirators in the entire suit. Both PPE heavy versions are suitable for decontamination in the chemical shower with peracetic acid. The different PPE versions and handling protocols have been tested in a study with volunteers in order to identify limiting factors for working in PPE and the impact on dexterity as well as on error rates in long working shifts (up to $6 \mathrm{~h}$; the regular working shift should not be longer than $4 \mathrm{~h}$ in the BSL-3 laboratory) [30].

For decontamination of personnel, 2\% peracetic acid is currently used in the chemical shower due to the shorter exposure time as compared to chlorine dioxide. For corpses, other decontamination agents that require a longer exposure time in order to be effective, such as chlorine dioxide, can be used. A smaller spray lock, which is operated with 2,200 ppm chlorine dioxide as a decontamination agent, is used for sample and material transfer (Fig. 2).

Validation of decontamination processes in the chemical shower and sample lock was performed according to the Association for Applied Hygiene (Verbund für Angewandte Hygiene, [VAH], Germany) guideline for the test procedures for disinfectants [31]. To simulate a realistic autopsy setting, 2 bacterial suspensions, i.e., Staphylococcus aureus (DSM 799) and Mycobacterium fortuitum (DSM 46621), were spiked with a high organic load ( $0.3 \%$ albumin and sheep erythrocytes, respectively). For validation of the decontamination processes used in the chemical shower, defined pathogen suspensions were applied to different critical parts of PPE heavy (i.e., bottom of shoes, side of the suit, and headpiece) and then airdried for $30 \mathrm{~min}$. After the fumigation and incubation steps of the decontamination process, the test spots were swabbed and the surviving bacterial fraction was determined by plating onto agar plates. The sample lock was also tested, and in that case the bacterial suspension was applied onto sample tubes. According to VAH guidelines, a decontamination process is successful when the disinfectant reduces the bacterial load by $\log 4$. The chemical shower and the sample lock allow for variation of different parameters in the decontamination processes, such as the incubation time of disinfectants and the type and concentration of disinfectant. Therefore, these factors can be adjusted freely according to the application and disinfectant used. Room decontamination with hydrogen peroxide $(8.0 \mathrm{~g} / \mathrm{min}$ for $3 \mathrm{~h}$ and $4.0 \mathrm{~g} / \mathrm{min}$ for $7 \mathrm{~h})$ was validated using Geobacillus stearothermophilus and Bacillus atrophaeus as bioindicators (APEX biological indicators for $\mathrm{H}_{2} \mathrm{O}_{2}$ vapor; MesaLabs). After validation of the negative pressure and filter system, the room and person decontamination, and training of the personnel, the BSL-3 laboratory was approved for operation by the authorities in December 2018.

\section{Conclusion}

This laboratory for highly infectious pathogens has currently the highest protection level in Austria and is used in the context of the COVID-19 pandemic, in addition to autopsies, for research and development projects and cooperation with institutions that do not have sufficient BSL-3 capacities. Several research collaborations are currently underway to test possible drugs and neutralizing antibodies against SARS-CoV-2 with other universities and companies. In addition, the laboratory is used to evaluate preanalytical requirements of diagnostic tests together with leading diagnostic manufacturers and to assess new decontamination processes. Due to the limited space available, the room and operational concepts were optimized in the best possible way leading to a design for BSL-3 laboratories that can be well established in health care environments, providing a high level of protection at reasonable costs. Experience acquired in performing 20 autopsies of COVID-19-deceased patients and several research projects requiring propagation of SARS-CoV-2 showed that the design of the laboratory was appropriate for the various types of work planned. However, the area 
of the airlock is very small so there is limited capacity to dry the PPE suits and powered air-purifying respirators after the chemical shower. Operational procedures were continuously optimized with increasing experience, and personnel had to be trained repeatedly. PPE light was appropriate for performing autopsies, and, as single-use equipment, it did not require cleaning. PPE heavy, particularly variant 1 , was found to be better suited for work with cultured virus than the full body ventilated variant 2 because of less impairment of movements and better dexterity compared to variant 2 . The powered air-purifying respirator in PPE heavy was superior to FFP3 masks not only in terms of providing greater protection from aerosols when working with a high-titer virus but also in reducing fatigue in long work shifts, and it should also be considered for autopsies. The availability of different PPE configurations proved to be essential because several PPE components were not available during the COVID-19 crisis. Furthermore, the chemical shower allowed reuse of both PPE-heavy variants, which enabled us to remain operationally independent of the PPE supply, at least for the most critical 2 months.

Lessons learned for future pandemics are that trained personnel and sufficient stocks of PPE are essential for a rapid and proper response, and that more emphasis should be placed on infectious disease pathology in general [10]. In particular, all residents in pathology (junior pathologists) need to be aware of safety procedures and they need to be trained by senior pathologists to do autopsies of infectious diseases. Furthermore, there is a need for more specialized BSL-3 capacities with increased measures for protection of personnel and the environment. The general issue in addressing highly pathogenic infectious disease challenges is that it is very expensive to maintain the infrastructure and regularly train personnel in times without need. Infectious disease research programs are therefore very important in the health care environment since they ensure the continuous availability of trained personnel that is experienced and at the forefront of knowledge. These specially skilled people including pathologists specialized in infectious diseases are needed to train others and for capacity building in case of new pandemics. Another underestimated factor is that capacities for specialized experiments have to be available locally since in the most critical phase there were travel restrictions, which did not allow international exchange of trained people or access to other laboratories.

\section{Acknowledgement}

The authors are very grateful to Dipl. Ing. Christoph Scharl for essential support and technical supervison of the construction of the laboratory, and to Dr. Penelope Kungl for proofreading this paper.

\section{Conflict of Interest Statement}

There are no conflict of interests.

\section{Funding Sources}

The work was funded in part by the EU research project ERINHA-Advance (grant agreement ID: 824061), and by establishment of virus cultures and development of assays for antiviral drug testing by MEFOgraz, Vereinigung Forschungsförderung Med Uni Graz, Austria.

\section{Author Contributions}

K.Z. initiated the design of the laboratory, acquired funding, and wrote this paper. M.L. essentially contributed to the design of the laboratory and contributed to the writing of this paper. C.L. was involved in validation of decontamination procedures and contributed to the writing of this paper. P.R. and G.G. established autopsy procedures in the laboratory and contributed to the writing of this paper.

\section{References}

1 Madhav N, Oppenheim B, Gallivan M, Mulembakani P, Rubin E, Wolfe N. Pandemics: Risks, impacts, and mitigation. In: Jamison DT, Gelband H, Horton S, Jha P, Laxminarayan R, et al., editors. Disease control priorities: Improving health and reducing poverty. Washington: The International Bank for Reconstruction and Development/The World Bank; 2017.

2 Gibb R, Redding DW, Chin KQ, Donnelly CA, Blackburn TM, Newbold T, et al. Zoonotic host diversity increases in human-dominated ecosystems. Nature. 2020 Aug;584(7821):398-402.

3 De Cock KM, Zielinski-Gutiérrez E, Lucas SB. Learning from the Dead. N Engl J Med. 2019 Nov;381(20):1889-91.

4 Wong JY, Kelly H, Ip DK, Wu JT, Leung GM, Cowling BJ. Case fatality risk of influenza A (H1N1pdm09): a systematic review. Epidemiology. 2013 Nov;24(6):830-41.

5 Charu V, Chowell G, Palacio Mejia LS, Echevarría-Zuno S, Borja-Aburto VH, Simonsen
L, et al. Mortality burden of the A/H1N1 pandemic in Mexico: a comparison of deaths and years of life lost to seasonal influenza. Clin Infect Dis. 2011 Nov;53(10):985-93.

6 Rajgor DD, Lee MH, Archuleta S, Bagdasarian N, Quek SC. The many estimates of the COVID-19 case fatality rate. Lancet Infect Dis. 2020 Jul;20(7):776-7.

7 Fauci AS, Lane HC, Redfield RR. Covid-19 Navigating the Uncharted. N Engl J Med. 2020 Mar;382(13):1268-9.
44

Pathobiology 2021;88:37-45

DOI: $10.1159 / 000513438$
Loibner/Langner/Regitnig/Gorkiewicz/ Zatloukal 
8 Calabrese F, Pezzuto F, Fortarezza F, Hofman P, Kern I, Panizo A, et al. Pulmonary pathology and COVID-19: lessons from autopsy The experience of European pulmonary pathologists. Virchows Arch. 2020:1-14.

9 Müller H, Dagher G, Loibner M, Stumptner C, Kungl P, Zatloukal K. Biobanks for life sciences and personalized medicine: importance of standardization, biosafety, biosecurity, and data management. Curr Opin Biotechnol. 2020 Oct;65:45-51.

10 Hofman P, Lucas S, Jouvion G, Tauziede-Espariat A, Chretien F, Cathomas G. Pathology of infectious diseases: what does the future hold? Virchows Arch. 2017;470(5):483-92.

11 Sapino A, Facchetti F, Bonoldi E, Gianatti A, Barbareschi M, Societa Italiana di Anatomia Patologica e Citologia - SIAPEC. The autopsy debate during the COVID-19 emergency: the Italian experience. Virchows Arch. 2020; 476(6):821-3

12 Wissenschaftlichen Dienste des Deutschen Bundestages. Zur Bewertung des COVID19-Infektionsgeschehens: Ausgewählte Quellen und Institutionen. 2020. Available from: https://www.bundestag.de/resource/bl ob/706214/3186743b43670ebb3d93c9566e39 eab5/WD-8-032-20-pdf-data.pdf.

13 Robert Koch Institut. Empfehlungen zum Umgang mit SARS-CoV-2-infizierten Verstorbenen. 2020. Available from: https:// www.rki.de/DE/Content/InfAZ/N/Neuartiges_Coronavirus/Verstorbene.html.

14 World Health Organization. Laboratory biosafety guidance related to coronavirus disease (COVID-19). 2020. Available from: https:// www.who.int/publications/i/item/laboratory-biosafety-guidance-related-to-coronavirus-disease-(covid-19).

15 Publications Office of the European Union Commission Directive (EU) 2020/739 of 3 June 2020 amending annex III to directive 2000/54/EC of the European Parliament and of the Council as regards the inclusion of
SARS-CoV-2 in the list of biological agents known to infect humans and amending Commission Directive (EU) 2019/1833. Luxembourg: Publications Office of the EU; 2020.

16 EMPL Press release. 11 June 2020. https:// www.europarl.europa.eu/news/en/pressroom/20200609IPR80804/employmentmeps-reach-consensus-with-commissionon-workers-health-and-safety.

17 World Health Organization. Laboratory biosafety manual. 3rd ed. Geneva: WHO Library; 2004.

18 Publications Office of the European Union. Commission Directive (EU) 2019/1833 of 24 October 2019 amending annexes I, III, V and VI to directive 2000/54/EC of the European Parliament and of the Council as regards purely technical adjustments (2020). Luxembourg: Publications Office of the EU; 2020.

19 Centers for Disease Control and Prevention. Collection and submission of postmortem specimens from deceased persons with known or suspected COVID-19. 2020. Available from: https://www.cdc.gov/coronavirus/2019-ncov/ hcp/guidance-postmortem-specimens.html.

20 Keten D, Okdemir E, Keten A. Precautions in postmortem examinations in Covid-19-related deaths: recommendations from Germany. J Forensic Leg Med. 2020 Jul;73:102000.

21 Hanley B, Lucas SB, Youd E, Swift B, Osborn M. Autopsy in suspected COVID-19 cases. J Clin Pathol. 2020 May;73(5):239-42.

22 Health and Safety Executive. Managing infection risks when handling the deceased: Guidance for the mortuary, post-mortem room and funeral premises, and during exhumation. Norwich: HSE; 2018.

23 Dijkhuizen LG, Gelderman HT, Duijst WL. Review: the safe handling of a corpse (suspected) with COVID-19. J Forensic Leg Med. 2020 Jul;73:101999.

24 Mao D, Zhou N, Zheng D, Yue J, Zhao Q, Luo $\mathrm{B}$, et al. Guide to forensic pathology practice for death cases related to coronavirus disease
2019 (COVID-19) (Trial draft). Forensic Sci Res. 2020 Apr;5(1):1-7.

25 Teresiński G, Jurek T. Recommendations of the Polish Society of Forensic Medicine and Criminology and National Consultant for forensic medicine with regard to performing forensic post-mortem examinations in case of confirmed COVID-19 disease and suspected SARS CoV-2 infections. Arch Med Sadowej Kryminol. 2019;69(4):147-57.

26 Santurro A, Scopetti M, D’Errico S, Fineschi V. A technical report from the Italian SARSCoV-2 outbreak: postmortem sampling and autopsy investigation in cases of suspected or probable COVID-19. Forensic Sci Med Pathol. 2020.

27 Osborn ML, Stewart R, Swift B, Youd E. Briefing on COVID-19: Autopsy practice relating to possible cases of COVID-19 (2019-nCov, novel coronavirus from China 2019/2020). 2020. Available from: https://www.rcpath. org/uploads/assets/d5e28baf-5789-4b0facecfe370eee6223/fe8fa85a-f004-4a0c-81ee$4 \mathrm{~b} 2 \mathrm{~b} 9 \mathrm{~cd} 12 \mathrm{cbf} /$ Briefing-on-COVID-19-autopsy-Feb-2020.pdf.

28 Lacy JM, Brooks EG, Akers J, Armstrong D, Decker L, Gonzalez A, et al. COVID-19: Postmortem Diagnostic and Biosafety Considerations. Am J Forensic Med Pathol. 2020 Sep; 41(3):143-51.

29 Hirschbühl K, Schaller T, Kling E, Märkl B, Claus R. Autopsy of patients with COVID-19: A balance of fear and curiosity. Pathol Res Pract. 2020 Aug;216(8):153039.

30 Loibner M, Hagauer S, Schwantzer G, Berghold A, Zatloukal K. Limiting factors for wearing personal protective equipment (PPE) in a health care environment evaluated in a randomised study. PLoS One. 2019 Jan; 14(1):e0210775.

31 Association for Applied Hygiene. Requirements and methods for VAH certification of chemical disinfection procedures. Wiesbaden: mph; 2015 . 